Archives de sciences sociales des religions

149 | janvier-mars 2010

Varia

\title{
L'amnésie de la remémoration dans la société tchèque*
}

Zdeněk R. Nešpor

\section{(2) OpenEdition}

12 Journals

Édition électronique

URL : http://journals.openedition.org/assr/21886

DOI : $10.4000 /$ assr. 21886

ISSN : $1777-5825$

Éditeur

Éditions de l'EHESS

Édition imprimée

Date de publication : 31 mars 2010

Pagination : 109-128

ISBN : 978-2-7132-2253-5

ISSN : 0335-5985

Référence électronique

Zdeněk R. Nešpor, "L'amnésie de la remémoration dans la société tchèque* », Archives de sciences sociales des religions [En ligne], 149 | janvier-mars 2010, mis en ligne le 03 décembre 2013, consulté le 19 avril 2019. URL : http://journals.openedition.org/assr/21886 ; DOI : 10.4000/assr.21886

(c) Archives de sciences sociales des religions 


\section{Zdeněk R. Nešpor}

\section{L'amnésie de la remémoration dans la société tchèque*}

Tout au long du $\mathrm{XX}^{\mathrm{e}}$ siècle, le sentiment religieux dans la société tchèque demeure relativement faible. L’indifférence générale envers l'Église catholique, pourtant confession théoriquement majoritaire, ainsi que l'intérêt pour l'Église tchécoslovaque, la plus prospère des Églises catholiques « nationales » nouvellement créées dans les États issus de l'Autriche-Hongrie, intriguaient déjà les intellectuels laïques de l'entre-deux-guerres ${ }^{1}$.

L'adoption quasi automatique de la thèse de la sécularisation a imposé l'idée d'une transformation rapide et large de la société tchèque (Davie, 2003, 61-75; Gorski, 2003 : 110-122); les pays tchèques sont devenus l'exemple largement discuté d'une sécularisation réussie, considérée comme une conséquence inévitable de la modernisation, sans tenir compte de l'orientation anticléricale du régime communiste établi par la force en 1948 (Kadlecová, 1972 : 119-134; Martin, 1978 : 50, 233-234). Cependant le paradigme de la sécularisation vient d'être considérablement mis en doute au cours des dernières décennies, en même temps que la problématique de la religiosité tchèque a cessé d'attirer l'attention des chercheurs ${ }^{2}$. Ce qui constituait autrefois un exemple par excellence, est devenu, dans les aperçus généraux de la situation religieuse du monde actuel, un fait marginal sans importance théorique. Tandis qu'en Slovaquie, ou en Pologne, la chute du communisme, en 1989, a entraîné un puissant rebond de la vie religieuse, attendu également dans d'autres pays postcommunistes, aucun renouveau d'une religiosité longtemps réprimée n'a eu lieu en République tchèque. Cela a valu une attention bien méritée aux autres pays postcommunistes de l'Europe

* Le présent article a été écrit dans le cadre du projet no 404/08/0029 de la Fondation de la République tchèque pour le développement de la science; un stage à l'École des Hautes Études en Sciences Sociales (EHESS), en 2006, a largement aidé à sa rédaction.

1. Le premier cas était souvent lié à l'identification des intellectuels tchèques influencés par Masaryk avec une religiosité hors de l’Église comme Emanuel Rádl (1922), le second cas était représenté, entre autres, par Ambrose Czakó (1925, pp. 69-79).

2. Le paradigme de la sécularisation a été abandonné, par exemple, par Peter L. Berger (1992) ou David Martin (1991) qui l'avaient autrefois suggéré ; parmi les sociologues de religion européens, il est défendu actuellement surtout par Steve Bruce (2002). 
centrale et orientale, dont par exemple un numéro monothématique de la revue Social Compass ${ }^{3}$, tandis que les appartenances et idées religieuses de la société tchèque restent peu connues.

Bien qu'il soit évident que l'évolution de la religiosité - y compris son abandon et/ou ses changements structuraux - a suivi des chemins bien différents dans chaque société moderne (Martin, 2005), il est possible, dans une certaine mesure, de comparer la situation tchèque avec le triomphe de la laïcité française. En effet, dans les deux pays, le catholicisme prédominait pareillement à l'époque moderne et aux $\mathrm{XIX}^{\mathrm{e}}$ et $\mathrm{XX}^{\mathrm{e}}$ siècles, et on y a observé un anticléricalisme dont la valeur était simplement inversée, et qui, en fait, reprenait un bon nombre de structures d'origine catholique ; enfin, l'histoire des deux pays est marquée par le protestantisme. Avant que le pouvoir n'impose le catholicisme, les deux pays ont eu leur minorité protestante dont une partie a réussi à survivre, en se cachant, à la Contre-Réforme, et dont l'héritage a pris une importance sociale qui dépasse largement le taux de pénétration du protestantisme dans la société. Il faut cependant souligner certaines différences entre les deux pays dont il faudrait explorer les causes. On se contentera ici d'en citer deux :

1 - Dans leur histoire, les deux peuples ont connu des guerres de religion, les succès du protestantisme et, plus tard, sa répression violente, mais seul le peuple tchèque dans sa quasi totalité - non seulement les protestants modernes marginaux, mais aussi des libéraux et même une bonne partie de catholiques s'est réclamé de "l'héritage protestant ", même si la définition de ce dernier est plutôt aléatoire.

2 - «L'athéisme » ou l'anticléricalisme existait dans les deux sociétés, mais dans la société tchèque il est incomparablement plus répandu, devenant une identité « positive » et ouvertement déclarée. Les Tchèques sont fiers de leur « athéisme " et s'en vantent volontiers, le considérant comme un signe de "progrès ».

Afin d'appréhender le faible niveau de religiosité institutionnalisée de la société tchèque, on partira de la thèse de Danièle Hervieu-Léger considérant la religion comme un lien de la mémoire collective dont l'importance sociale tend à disparaître (Hervieu-Léger, 1993 ; Davie, 2000), ce processus étant, dans le cas tchèque, renforcé par diverses tentatives de "revitaliser " les traditions religieuses. L'amnésie religieuse dont la société tchèque est frappée, résulte paradoxalement des mesures trop souvent répétées visant à imposer d'autorité des mémoires religieuses. En même temps, il faut évoquer la critique du paradigme de sécularisation par le sociologue américain José Casanova : celui-ci estime que la thèse de sécularisation, loin de décrire l'évolution socioculturelle, fonctionne

3. Social Compass, 49, 2002, 4. La situation religieuse actuelle de l'Europe centrale et orientale a été également l'objet des travaux d’Irena Borowik \& Miklós Tomka (2001), José Casanova (1996), Mary L. Gautier (1997), Pippa Norris \& Ronald Inglehart (2004, pp. 111132), Detlef Pollack (2003), Sabrina Ramet (1998), etc. 
comme une prophétie qui s'accomplit d'elle-même à force d'être répétée. Pour lui, la sécularisation n'est pas une conséquence automatique de la modernisation comme le sont l'industrialisation, l'urbanisation, les réformes de l'enseignement scolaire ou autres, mais le triomphe d'un paradigme discursif accompagnant le processus de modernisation dans les pays occidentaux (Casanova, 1994 : 211-234).

Une grande partie de la société tchèque, fatiguée par des tentatives diverses, et souvent contradictoires, de renouvellement des traditions religieuses, a adhéré à la critique moderniste de la religiosité institutionnalisée dont on observe les conséquences jusqu'à présent et qui provoque des tensions entre les partisans et les adversaires de la religion. Cela ne signifie pas que seuls les moyens idéologiques venant "d'en haut» sont la cause de la laïcisation historique de la société tchèque.

Les recensements comportant la question de l'appartenance religieuse, telle qu'elle est ressentie par le sujet donné, ainsi que les statistiques internationales, montrent la République tchèque comme un des pays les plus sécularisés du monde. Dans le cadre du recensement tchèque du 1991, 44 \% des habitants déclaraient appartenir à une Église (et pour $89 \%$ d'entre eux, il s'agissait de l'Église catholique) et $40 \%$ se définissaient comme athées. Mais, dix ans plus tard, ce rapport est de $32 \%$ par rapport à $59 \%$ en faveur d'un athéisme déclaré. Contre toute attente, l'échec du communisme n'a provoqué aucun renouveau religieux et aucun renouveau des Églises chrétiennes venant de l'Est, rêvé par certains intellectuels occidentaux, n'a eu lieu (Weigel, 2004). La diminution du nombre de fidèles affiliés à une Église au cours des années quatre-vingt-dix est imputable au changement des générations (qui entraîne également un recul de la religion institutionnalisée en Europe occidentale) mais aussi et surtout aux facteurs plus spécifiquement postcommunistes ou exclusivement tchèques. L'héritage du communisme s'est traduit par l'incapacité des Églises à adopter une attitude critique envers leur propre passé et envers leur rôle de laquais du pouvoir sous le régime communiste ou éventuellement réagir de manière appropriée aux défis d'une société démocratique. Pour ces deux raisons, les Églises établies ont perdu leur crédit auprès d'une bonne partie des populations en Europe orientale (Grajewski, 1999).

Les Églises chrétiennes comptent parmi les organisations sociales les moins crédibles et une grande partie de la société doute également de leur capacité à résoudre les problèmes moraux, familiaux ou sociaux. Les enquêtes de l'International Social Survey Program (ISSP) démontrent combien le taux de confiance dans les Églises et dans les organisations religieuses a diminué au cours des années quatre-vingt-dix ; seul un quart de la population les juge aujourd'hui capables d'apporter des solutions aux problèmes moraux et familiaux et $13 \%$ seulement aux problèmes sociaux ; ce n'est qu'à propos de la capacité des Églises à satisfaire les besoins spirituels que la confiance en elles diminue le moins $(57 \%)$. Pourtant, la laïcisation en progrès n'est pas nécessairement le signe d'un vrai athéisme. Une enquête internationale menée par l'agence GfK, en automne 
2004, a démontré que seuls $32 \%$ des habitants tchèques croient en un Dieu créateur, ce qui représente le taux le plus faible des vingt et un pays ayant participé à l'enquête, parmi lesquels la République tchèque était le seul où le nombre de non-croyants (en un Dieu personnel) dépassait celui des croyants ${ }^{4}$. Cependant, l'incroyance strictement doctrinale, observée couramment même parmi les personnes qui déclarent adhérer à l'une ou l'autre des Églises, est liée à une attitude générale envers celles-ci. D'un autre côté, en effet, l'enquête faite par l'ISSP, en 1998, a révélé un taux élevé de croyances modernes, syncrétiques ${ }^{5}$, et cette tendance continue à augmenter, notamment parmi la population plutôt jeune, urbaine, de niveau d'éducation supérieur. Tandis que la religiosité institutionnalisée et les croyances traditionnelles tendent à faiblir, des formes religieuses nouvelles, désignées souvent par le terme "spiritualité » (Nešpor 2004 : 282-285) prennent leur place. Dans la société tchèque, les vrais athées sont aussi rares que les croyants orthodoxes et pratiquants; en revanche, on constate une multiplication de diverses formes de religiosité/spiritualité privées ${ }^{6}$.

\section{Les traditions religieuses d'un peuple dit sans religion}

Dans son interprétation de la révolution de 1989 et de la transformation postcommuniste de la société tchèque, Ladislav Holy, anthropologue social britannique d'origine tchèque, a consacré une place importante aux symboles nationaux (1996:9). Les Tchèques avaient à leur disposition toute une série de symboles d'origine religieuse, par exemple des saints catholiques : saint Venceslas, considéré comme une incarnation de l'indépendance tchèque, dont la statue a servi de point de ralliement aux manifestants, ou encore les saints Cyrille et Méthode et sainte Agnès de Bohême, canonisée en 1989, dont les célébrations devinrent l'expression de l'opposition au régime communiste. Non moins important - quoique hétérodoxe du point de vue catholique - le personnage de Jan Hus, réformateur religieux, esprit hors du commun, symbole de l'indépendance tchèque, dont le monument praguois constitua un autre point de rassemblement des manifestations. S'y ajoutent d'autres héros chers au cœur du peuple tchèque, tels le roi de Bohême et empereur romain Charles IV, homme éminemment pieux comme il se devait au Moyen Âge, ou encore Thomáš Garrigue Masaryk, premier Président de la Tchécoslovaquie, qui s'opposait à l'Église mais certainement pas au christianisme. Cela fait tout de même beaucoup de symboles empruntés aux traditions religieuses pour un peuple supposé très sécularisé.

Ces traditions contribuaient toutes à une Great Czech Nation mythologisée et nationaliste aspirant depuis toujours à la démocratie et à l'humanisme, et

4. http://www.gfk.hr/press_en/religion.htm

5. Ainsi $49,7 \%$ de la population croient aux amulettes, $50 \%$ aux horoscopes et $69,7 \%$ à la divination, Dana Hamplová (2000, p. 45).

6. Selon Detlef Pollack (2003), la situation est comparable dans d'autres pays de l'Europe orientale. 
représentant une force motrice (quoique cachée) du progrès de l'Europe sinon de l'humanité entière (Holy, 1996 : 118-137). Des réminiscences de la conception herderienne des Slaves - devenues au XIXe siècle un élément constitutif de l'histoire canonique tchèque élaborée par l'historien František Palacký, et complétée par le philosophe Masaryk, contribuant encore de nos jours à la construction de l'identité nationale - ont permis d'utiliser, d'une façon nouvelle et au détriment du christianisme institutionnalisé, les connotations religieuses des symboles d'identification cités (et d'autres). C'est ici qu'il faut chercher l'origine de "l'athéisme » tchèque ou plus exactement ce qu'on désigne par ce nom, bien que des auteurs et chercheurs catholiques spécialisés en histoire du catholicisme aient eu tendance à faire remonter son origine beaucoup plus loin dans le passé, la voyant dans la révolte hussite contre l'Église au Moyen Âge (Rémond, 1998 : 278).

$\mathrm{La}$ « pré-Réforme » hussite, confondue plus tard avec un luthérianisme modéré de type mélanchtonien, a, certes, été dirigée contre l'Église, nullement au nom d'une nation ou d'une émancipation sociale, encore moins au nom d'un progrès d'orientation antireligieuse (même si toutes ces explications ont été évoquées au cours des XIX et XX ${ }^{\mathrm{e}}$ siècles), mais au nom du mouvement des Tchèques « fidèles » au sens religieux du terme, fideles Bohemi. Au regard des Hussites, la Bohême était un regnum christianissimum qui n'a pas perdu sa religiosité au début des temps modernes, lors de la re-catholicisation forcée de la plupart des habitants, lorsque les protestants convaincus furent contraints à l'exil. Des observateurs étrangers se sont émus a contrario d'une religiosité bigote et superstitieuse de la société tchèque de l'époque (Maur, 2003 : 89-90), et, plus tard, c'est avec une répugnance profonde que les tendances antireligieuses de la Révolution française ont été reçues dans les pays tchèques (Kutnar, 2003 : 150-158).

Les réformes de l'homme des Lumières qu'était l'empereur Joseph II, et la manière radicale avec laquelle celles-ci furent imposées, ont porté un coup beaucoup plus dur à la légitimation religieuse de l'Ancien Régime, dans la mesure où elles ont mis en doute la croyance populaire traditionnelle de l'époque baroque - alors qu'elles visaient pourtant à approfondir un «vrai » christianisme. La tolérance religieuse joséphiste de 1781 a autorisé le luthéranisme, le calvinisme et l'Église orthodoxe, bien qu'un assez petit nombre de personnes y aient adhéré (environ $2 \%$ seulement de la population) même si le catholicisme demeurait religion d'État. La confession cessait de représenter l'identité unissant la société dans son ensemble. Dès le début du XIX ${ }^{\mathrm{e}}$ siècle, ce rôle unifiant s'était progressivement déplacé pour être joué dorénavant par la conscience nationale, d'abord parmi les intellectuels et les élites, puis, à partir des années 1840, grâce à l'influence de ces derniers, au sein des couches populaires de la société ${ }^{7}$. "Le printemps

7. La tolérance religieuse en tant que première phase de sécularisation européenne est décrite plus en détail par René Rémond, qui prête également attention à sa version austrohongroise (1998, pp. 53, 61) ; Miroslav Hroch (2003), voit l'origine du nationalisme tchèque dans la crise de l'Ancien Régime. 
des nations » de l'Europe centrale a singulièrement accentué l'ancrage dans la langue et dans l'histoire des nouvelles identités nationales.

Cependant, dans le cas tchèque, cette légitimation même a conduit à un constat paradoxal : la grandeur historique et l'importance européenne, ainsi que les institutions juridiques, sociales et culturelles de l'État tchèque au Moyen Âge, n'étaient pas liées au catholicisme, prédominant au XIX ${ }^{\mathrm{e}}$ siècle, mais au hussitisme et, plus tard, au protestantisme tchèque. De même, la langue et la littérature tchèques avaient connu leur plus grand essor durant la période hussite, au $\mathrm{XVI}^{\mathrm{e}}$ siècle et au début du XVII ${ }^{\mathrm{e}}$ siècle, lorsque le hussitisme fut transformé en une Église utraquiste (majoritaire) et en l'Union des Frères (ou Frères tchèques) plus rigoureuse et plus tard au sein même des exilés protestants du XVII ${ }^{\mathrm{e}}$ siècle, alors que la re-catholicisation se caractérisait par une germanisation et un déclin culturel. Ce n'est qu'en 1915 qu'Alois Jirásek, écrivain romantique populaire, qualifie la période de re-catholicisation forcée de "Ténèbres ", terme qui allait bientôt passer dans les manuels d'histoire, bien qu'au milieu du siècle précédent déjà, les catholiques tchèques aient été amenés à demander pardon pour les méfaits de la Contre-Réforme (Putna, 1998 : 152). Ainsi, la montée du nationalisme tchèque et sa légitimation historique par la Réforme contribuèrent-elles à ébranler le catholicisme de l'époque. Mais aucune version tchèque du mouvement allemand Los von Rom, présentant le protestantisme (unifié) comme Église nationale et capable de provoquer des conversions en masse, n'a vu le jour.

Au lieu de cela, s'est consommée la rupture interne de la société avec le catholicisme, présenté comme anti-tchèque et désuet (Putna, 1998). Le catholicisme ultramontain semblait trop autoritaire et rigide aux libéraux, les nationalistes dénonçaient l'union du trône autrichien et de l'autel ainsi que la politique gouvernementale anti-tchèque dans l'attribution des hautes fonctions ecclésiastiques. Tous ensemble étaient persuadés (plutôt à juste titre) du caractère "démodé » du catholicisme de l'époque. Les intellectuels catholiques ont tenté de présenter leurs propres vues sur l'histoire nationale, une histoire alternative faisant la part belle au christianisme médiéval et au culte des saints nationaux, mais sans obtenir un retentissement notable (Pabian, 2005). L'accent mis sur l'histoire non catholique du peuple tchèque, ainsi que les intérêts politiques actuels au XIXe siècle, ont donc ébranlé l'identité catholique de la majorité de la société sans pour autant proposer une alternative ecclésiale réelle. Aussi la conscience nationale et la foi en l'humanisme et le progrès ont-elles forgé la nouvelle "idéologie centrale ». Qu'on ait pu y trouver des liens avec la Réforme tchèque et l'Unité des Frères y aura joué un rôle essentiel. 


\section{Les catholiques éclairés à la recherche de la religion}

Au début de l'époque moderne, et jusqu'à la moitié du XIX ${ }^{\mathrm{e}}$ siècle, il n'était guère évident de considérer la révolution hussite et la société multiconfessionnelle à laquelle celle-ci avait donné naissance ${ }^{8}$ comme un sommet de l'histoire tchèque. Les acteurs catholiques de la Contre-Réforme considéraient bien sûr le hussitisme et le protestantisme comme des mouvements hérétiques et cherchaient à démontrer le caractère profondément catholique du peuple tchèque en faisant passer la Réforme pour une époque funeste née des influences étrangères (les Vaudois, les doctrines de Wycliff). Pourtant, même les protestants, obligés de s'exiler après la bataille de la Montagne Blanche, ne se réclamaient pas particulièrement du hussitisme. En effet, les utraquistes, pour la plupart réfugiés dans la Saxe voisine, avaient dû s'accommoder du luthéranisme orthodoxe de la Formula concordiae, tandis que les fidèles de l'Union des Frères installés en Pologne, aux Pays-Bas ou en Angleterre, se sont tôt tournés vers le calvinisme de l'époque. Alors que Luther reconnaissait explicitement l'héritage du hussitisme après sa polémique avec Eck à Leipzig, les protestants commençaient à se rendre compte (déjà dans l'œuvre de Jacob Lenfant - 1783-1784 -, sinon avant) que les hussites avaient été beaucoup plus proches du catholicisme qu'eux-mêmes. Autrement dit, ils commençaient à abandonner l'idée selon laquelle les hussites auraient été leurs éminents précurseurs au nom de l'idée d'une ecclesia semper reformanda.

Une seule exception : les piétistes, dont certains se réclamaient de la Réforme tchèque et notamment de l'Union des Frères - Nikolaus Ludwig von Zinzendorf et l'Unitas fratrum nouvellement créée qui s'appuyaient également sur la tradition du biblicisme tchèque (Nešpor, 2006 $)^{9}$, considérant comme leur priorité les missions religieuses dirigées vers leurs anciens coreligionnaires, où ils renouvelaient ou réintroduisaient les traditions auprès des non-catholiques tchèques non déclarés. Les missions religieuses secrètes du XVIII ${ }^{\mathrm{e}}$ siècle, ainsi que le trafic de livres interdits dans les régions re-catholicisées, ont provoqué une nouvelle vague d'émigration religieuse et, en même temps, ont renforcé le non-catholicisme clandestin en Bohême et en Moravie.

Dans le premier cas, les émigrés ont dû adhérer à une confession officielle, d'où diverses querelles et scissions, une partie penchant vers les luthériens, une autre vers les réformés et une troisième se prononçant en faveur des Frères

8. Au milieu du XV siècle, le hussitisme premier s'est divisé en une Église utraquiste, majoritaire (dont l'appellation fait référence à la communion sub utraque specie) et devenue, en fait, une sorte d'Église nationale, et une Union des Frères, plus stricte, qui a rompu tous les liens avec l'Église romaine; parallèlement, une petite mais influente minorité catholique subsistait toujours dans le pays. Sous l'influence de la Réforme européenne, l'utraquisme lui-même allait se diviser en une majorité d'inspiration mélanchtonienne du luthérianisme (que Hrejsa appelle néo-utraquistes) et une minorité fidèle à la confession originale, plus proche du catholicisme : les paléo-utraquistes. À la fin du XVI $\mathrm{I}^{\mathrm{e}}$ siècle, l'Union des Frères est devenue plus ou moins calviniste, tandis que d'autres groupes religieux sont apparus.

9. Sur l'exil religieux tchèque au XVIII e siècle, voir Ducreux (1999). 
(de Herrnhut). Cependant, tous ces groupes revendiquaient l'héritage exclusif de la première Union des Frères qu'ils considéraient comme le sommet de la Réforme tchèque, sans tenir compte de sa marginalité d'autrefois. Dans le milieu re-catholicisé, rien de tel n'était possible, la question de la "véritable " succession de l'Union des Frères n'est apparue qu'après la promulgation de l'Édit de tolérance par Joseph II en 1781. Les non-catholiques, jusqu'alors secrets, ont alors eu la possibilité d'adhérer à la confession d'Augsbourg ou à la confession helvétique et les pasteurs des deux confessions ont commencé à se disputer "l'héritage » de l'Union des Frères ${ }^{10}$.

Ne voulant pas assister passivement à ce " combat pour les âmes " déclenché après la promulgation de l'Édit de tolérance et craignant une agitation religieuse et un prosélytisme au profit des confessions protestantes, des intellectuels catholiques publièrent des ouvrages polémiques visant à démontrer que l'unique religion juste était celle des catholiques. Les partisans des réformes religieuses de Joseph II, despote modérément éclairé, voulaient supprimer toutes les « superstitions " et les "pratiques magiques » baroques, limiter les pèlerinages, les ordres monastiques, laïques et les associations et fraternités religieuses, réformer le culte, etc. (Winter, 1943). Dans cette optique, la religion devait être réduite à ses aspects positifs : tolérance chrétienne, amour du prochain, missions éthiques et sociales, tandis que la différenciation dogmatique et la piété mystique se manifestant par des éléments " orthopraxiques " étaient reléguées au second plan. Quoique les réformateurs rationalistes se fussent considérés comme de bons catholiques, ils cherchèrent à imposer d' " en haut " une conception du catholicisme complètement différente de celle qui prédominait dans la société tchèque à cette époque, ce qui a finalement considérablement affaibli l'autorité religieuse (Hroch, 2003, p. 192).

Ces catholiques éclairés ne comptaient pas faire l'effort des luthériens et des protestants réformés pour "s'approprier " l'héritage de l'Union des Frères! Cependant, par leur désaccord avec le catholicisme baroque, ils s'inscrivaient nécessairement dans la lignée de la relative tolérance religieuse de la Bohême hussite et utraquiste qui l'avait précédé. Même s'ils condamnaient le fanatisme du premier hussitisme, ils approuvaient la critique de l'Église catholique par Hus et son recours au Dieu unique, juge de la vraie foi. Dans le sillage de Lenfant, les intellectuels catholiques, tels A. Zitte et Kaspar Royko, ont considéré Jan Hus comme "plutôt catholique " et critiqué l'Église dépravée qui l'avait envoyé au bûcher, contribuant ainsi involontairement à sa popularisation (Royko, 1781-85; Zuber, 2003 : 270). On découvre des traces de ce nouveau regard, plus positif, sur le hussitisme modéré notamment dans les différentes éditions du manuel Kurzgefaßte Geschichte der Böhmen... ${ }^{11}$, écrit par Franz Martin Pelzel, qui critiquait résolument les jésuites - allant jusqu’à écrire dans ses mémoires que

10. Le choix de la confession se faisait surtout selon la manière d'exécuter les rites religieux : voir Institoris (1783). Pour un aperçu général, voir Nešpor (2006, pp. 387-396).

11. La première édition a paru en 1774 ; d'autres éditions, remaniées, ont suivi en 1779 et 1782 . 
" chaque Tchèque était un peu hussite ». Curieusement, même le gouvernement autrichien a tenté de se réapproprier l' " héritage des hussites " lors des guerres napoléoniennes, en utilisant les réminiscences historiques des succès militaires de Jan Žižka pour inciter les Tchèques à la défense du territoire.

Ainsi un peuple fidèle au catholicisme a-t-il commencé à prendre conscience - en grande partie grâce à l'action des ecclésiastiques - qu'une partie de son histoire, à laquelle le Réveil national naissant se référait, n'était pas du tout catholique et cette prise de conscience devait avoir des conséquences néfastes sur l'évolution ultérieure du catholicisme tchèque. Les théologiens catholiques euxmêmes ont pris la mesure du danger au plus tard au début des années 1840. Si La Revue du clergé catholique (Časopis pro katolické duchovenstvo), l'unique magazine théologique tchèque, contenait jusqu'alors surtout des proclamations patriotiques s'appuyant sur la nécessaire solidarité des prêtres avec la nation, une partie du clergé attira plus tard l'attention sur le préjudice qu'un nationalisme se réclamant du hussitisme pouvait infliger à l'Église. Au lieu de distinguer les "vraies » des « fausses " Lumières - les secondes étant liées aux excès antireligieux de la Révolution française - on s'est mis à distinguer un "vrai » et un "faux » patriotisme, toujours avec les mêmes arguments, voire dans les mêmes termes.

\section{Peut-on faire d'une nation catholique une nation protestante?}

Cette évolution idéologique profitait évidemment aux Églises protestantes marginales, bien qu'elles-mêmes n'y participassent pas beaucoup. Par exemple, la thèse d'une opposition supposée entre Jan Hus et saint Jean Népomucène - selon laquelle le culte népomucien aurait été instauré à l'époque de la ContreRéforme pour remplacer celui de Jean Hus - devait devenir plus tard une des pierres angulaires de la conception protestante de l'histoire tchèque et la base de toute critique anticatholique libérale. Celle-ci n’a pas été inventée en 1849 par un protestant, mais par Ferdinand Břetislav Mikovec, auteur dramatique aux idées libérales (Vlnas, 1993 : 229-230). Ce qui était d'autant plus facile que la théologie protestante de l'époque ainsi que certains exemples venus de l'étranger (telles les œuvres favorables aux protestants publiées par le mouvement dit $\mathrm{du}$ «catholicisme allemand ») rendaient possible et même provoquaient cette association du nationalisme et du modernisme libéral avec le protestantisme, laquelle valorisait le passé réformiste des protestants tchèques et représentait pour eux une possibilité d'améliorer leur statut actuel. Une brochure anonyme, Le message sincère d'un protestant tchèque aux compatriotes catholiques, incitait ouvertement, en 1849, les catholiques à changer de camp (Lukášek, 1927 : 89-90). Au cours de la révolution de 1848, il y eut des tentatives multiformes, quoique finalement vaines, d'une "re-protestantisation » du peuple tchèque de la part d'une partie du clergé protestant, visant à émanciper les Églises protestantes et, éventuellement, à les unifier. 
L'ouvrage, La conception de l'année 1620, publié avec un sous-titre révélateur "Les ravages exercés par les Jésuites en Bohême et en Moravie ", offre un exemple de l'anticatholicisme libéral soutenu par des institutions protestantes. Ce texte dépeint l'histoire de la religion tchèque dans les termes d'un nationalisme exacerbé, dénonçant sans équivoque la Contre-Réforme au profit de la période hussite (Wysomýtský, 1849). Les Tchèques y sont décrits comme une nation autrefois démocratique et puissante qui avait connu son âge d'or à l'époque de la prétendue tolérance religieuse post-hussite et qui avait fini écrasée par le pouvoir militaire et politique germanique d'une part et par le catholicisme jésuite de la Contre-Réforme de l'autre. Selon son auteur, seuls le Réveil national de la première moitié du XIX siècle et l'évolution politique qui s'ensuivrait - laquelle devait mener à la démocratie, à l'émancipation nationale, à une meilleure éducation populaire et, au moins, à une réforme profonde de l'Église catholique sinon à un changement d'identité confessionnelle de la nation entière - offraient la possibilité de mettre un terme aux " deux siècles d'esclavage ", ce qui du coup profiterait à tous les peuples slaves. Si les théologiens des Lumières concevaient leurs réformes pour le bien du catholicisme, il n'en allait pas de même pour leurs successeurs, et cette tendance ne cessa de croître tout au long de la seconde moitié du XIX ${ }^{\mathrm{e}}$ siècle.

C'est ainsi que Masaryk, dans son ouvrage La Question Tchèque, a pratiquement repris tous ces arguments : il y qualifie le Réveil national de "continuation " de la Réforme tchèque, notamment celle des traditions de l'Union des Frères, et met l'accent sur la mission humaniste que la nation tchèque, guidée par la Providence, est censée accomplir dans l'histoire mondiale (Masaryk, 1990). Les libéraux ont commencé à considérer l'opposition des hussites à l'Église romaine comme un moment précurseur du rationalisme moderne et les guerres hussites comme un combat contre les Allemands, pour sauver la nation tchèque. En revanche, les protestants, n'ayant pas réussi à imposer l'unification de leurs deux Églises et encore moins à "re-protestantiser » le peuple tchèque, ont eu recours à une nouvelle confessionnalisation et ont recommencé, au cours de la seconde moitié du XIX siècle, à mettre en avant non seulement les différences entre les luthériens et les réformés, mais surtout le droit exclusif de l'une de ces Églises à «l'héritage » de l'Union des Frères.

\section{D'autres identités nationales et religieuses}

Cependant, les Tchèques qui, au cours du XIX ${ }^{\mathrm{e}}$ siècle, commençaient à concevoir leur histoire dans un esprit anticatholique et pour qui la fonction d'identité religieuse a été remplacée par celle de l'identité nationale (Nešpor, 2004 : 282285), n'étaient pas les seuls à revendiquer l'héritage des hussites à l'époque du " printemps des nations ». Les Allemands des pays tchèques, représentant un quart à un tiers de la population du royaume, critiquaient une foi de façade des 
Tchèques, qu'ils étaient enclins à faire remonter à un passé ancien. Dans cette optique, le hussitisme apparaissait comme une phase initiale de la réforme luthérienne, la seule à avoir retenu l'idée d'une réforme de l'Église tandis que les Tchèques l'avaient "trahie " en l'abandonnant au cours de la Contre-Réforme. C'est d'ailleurs la raison pour laquelle certains Allemands des pays tchèques - attirés par le catholicisme allemand ou, plus tard, par le mouvement Los von Rom et qui avaient créé la Vieille Église catholique (quand il ne s'agissait pas carrément de luthériens) - refusaient la coloration nationale que la grande partie de la population tchèque de la seconde moitié du XIXe siècle projetait sur Jan Hus et les hussites, comme figures d'une " pré-Réforme » (Kaiserová, 2003 : 131-138).

Bien que l'unification des luthériens avec les réformés tchèques se fût révélée impossible au cours du XIX ${ }^{\mathrm{e}}$ siècle, une partie des intellectuels protestants continuait de la désirer et d'espérer qu'elle leur offrirait une plus grande marge de manœuvre pour sortir de leur statut minoritaire. Pour justifier cette union hypothétique, ils devaient renoncer à "l'héritage de l'Union des Frères ", source de controverses entre les deux Églises, et trouver un autre facteur de légitimation historique. Cette tâche difficile a été finalement accomplie par Ferdinand Hrejsa, historien protestant, qui a souligné le caractère original et national d'un néoutraquisme dont la profession de foi, la Confession tchèque de 1575 , lui paraissait être un sommet historique de la tolérance religieuse, puisqu'elle avait « englobé » diverses confessions en leur permettant de coexister (Hrejsa, 1912) ${ }^{12}$.

La naissance, en 1918, d'une Tchécoslovaquie indépendante a donné une grande impulsion à l'unification des deux Églises protestantes : les luthériens et calvinistes ont fondé ensemble l'Église protestante des Frères Tchèques qui avait rejeté ostensiblement la confession d'Augsbourg aussi bien que la confession helvétique, pour adopter la Confession tchèque déjà mentionnée et celle de l'Union des Frères ${ }^{13}$. Mais, fait symptomatique, l'union protestante de 1918 ne regroupait que les temples de langue tchèque, tandis que les protestants de langue allemande n'y adhérèrent pas et formèrent eux-mêmes une Deutsche evangelische Kirche autonome ; les protestants de Silésie gardèrent également leur autonomie, l'identité luthérienne étant plus importante à leurs yeux qu'une conscience nationale tchèque, allemande ou polonaise. L'Église protestante des Frères Tchèques, dont le premier président tchécoslovaque Masaryk était membre, chercha à tirer profit de "l'héritage national protestant ", mais sans grand succès. Des brochures populaires de l'époque associèrent le slogan antiautrichien "loin de Vienne » avec un autre - Los von Rom (Stržínek, 1921) - mais malgré l'abandon en masse

12. Pour les aspects théologiques de l'œuvre de Ferdinand Hrejsa, voir Rudolf Říčan (1948, pp. 353-354).

13. L'adoption des anciennes confessions avait surtout un caractère déclaratif et nationaliste, la nouvelle union des Églises restant en fait plus proche du luthéranisme actuel et, surtout, du calvinisme. 
de l'Église catholique - au bout de quelques années plus d'un million de fidèles l'avaient quittée, dont vingt mille seulement d'une langue autre que tchèque ou slovaque - seules plusieurs dizaines de milliers de personnes rejoignirent l'Église nationale protestante.

Une autre tentative de réunir les identités nationale et religieuse après la naissance de l'État tchécoslovaque est restée également sans succès : la fondation, en 1920, de l'Église tchécoslovaque par certains ecclésiastiques catholiques mécontents. Bien que la sécession des curés non reconnus par Rome leur ait valu le ralliement de plusieurs centaines de milliers de catholiques, elle ne parvint pas à ébranler la position largement majoritaire de l'Église catholique. En outre, si le catholicisme n'était qu'une formalité pour une grande majorité de ses fidèles, comme le démontrent les premières enquêtes sociologiques sérieuses sur la religiosité tchèque (Sekera, 1932 ; Nešpor, 2007), il en était pratiquement de même avec les membres de la nouvelle Église qui se référait à la conception masarykienne de l'Histoire sans pour autant séduire son auteur. Après une période où cette nouvelle Église flirta avec l'Église orthodoxe, un paradigme utilitariste y prit le dessus, incitant les gens à " adhérer à l'Église, sans qu'il soit tenu compte de leurs convictions intimes » et provoquant des critiques de la part des intellectuels (Peroutka, 1991 : 901). L’Église tchécoslovaque tenta, sans grand succès, de tirer profit tant du christianisme mystique et individuel que d'une interprétation nationaliste du hussitisme dont pourtant elle considérait le "legs protestant » comme hérétique et moralement dégénéré.

La plupart des Tchèques sont restés - pour la forme - catholiques mais leur véritable "religion » était un nationalisme marqué par une vision du caractère exceptionnel et progressiste de leur nation, par une attitude négative envers les Allemands des pays tchèques et par un paternalisme envers leurs " jeunes frères " slovaques. Une conception romantique et nationaliste de l'histoire tchèque, dont le "fondement » a été " démontré » par la création d'un État indépendant, prédominait dans le discours public et est devenu un élément fondamental de l'enseignement scolaire, de sorte que l'interprétation catholique de l'histoire nationale a été définitivement rejetée. Dans cette optique cependant le hussitisme a perdu son caractère religieux : il sera dorénavant appréhendé comme un mouvement "progressiste ", ipso facto anticatholique et nationaliste, donc anti-allemand ${ }^{14}$.

\section{Le marxisme et son héritage}

Après le coup d'État communiste, en 1948, le " mouvement révolutionnaire des Hussites ", comme on appelait désormais officiellement cet épisode de l'histoire tchèque, sera considéré comme une révolte sociale antireligieuse, puisque

14. Le caractère religieux de la révolution hussite a, de nouveau, été souligné, en 1971, par František Šmahel. 
dirigée contre l'Église, qui n'avait tout simplement pas pu se départir de traditions populaires issues du Moyen Âge (Macek, 1952 ; Kalidova, 1961). Les idées fondamentales de la conception masarykienne de l'histoire tchèque, qui mettait en avant l'époque hussite ainsi que l'idée du progrès humaniste, ont été conservées, même s'il fallait omettre le nom de leur auteur. La Providence a été également occultée mais, en fait, elle a revêtu l'aspect de l'idée, implicitement religieuse, du progrès et d'une croyance eschatologique profane. Tandis qu'au Moyen Âge la religion pouvait se manifester, ne fût-ce que superficiellement, dans le mouvement social, la société socialiste, beaucoup plus progressiste, devait bien entendu y renoncer complètement et le régime ne manquait pas d'y contribuer par le biais des mesures répressives contre les Églises et leurs fidèles (Cuhra, 2001). En conséquence, on abandonnait massivement le catholicisme de façade, alors que la vraie foi religieuse de la grande majorité des gens était morte depuis longtemps déjà, au moins en ce qui concerne la religion ecclésiale.

L'unique enquête sociologique sur le sentiment religieux, faite à cette époquelà, montre qu'entre 1946 et 1963 le taux de religiosité (organisée dans des Églises) a continué à décroître ; le taux d'athées et celui de croyants atteignaient l'un et l'autre $30 \%$, tandis que les $40 \%$ restants se situaient entre ces deux pôles ; près d'un tiers des croyants l'étaient de façon non conformiste (Kadlecová, 1967). La conception marxiste de la classe ouvrière en tant qu' " avant-garde " du reste de la société a été passablement ternie par le fort sentiment religieux répandu parmi les ouvriers - seuls $24 \%$ d'ouvriers pouvaient être considérés comme athées, ce qui était inférieur au cas des retraités (29\% d'athées) tandis qu'un taux plus élevé d'athées dans les couches de population de niveau d'instruction supérieur et habitant les villes pouvait être une conséquence de l'éducation (interprétation de l'époque) aussi bien que celle de la crainte de perdre un emploi plus qualifié à cause de la religion. En tout cas, l'enquête aura confirmé les progrès de la sécularisation de la société tchèque dans le sens de sa laïcisation.

La situation était tout à fait différente en ce qui concernait la religiosité implicite ou l'influence des organisations religieuses sur celle des groupes ou identités sociales, ethniques, de classe, etc. (dévotion "néo-durkheimienne ») (Taylor, 2002 : 77-79). Si le régime communiste combattait la religion organisée, qu'il n'avait pas interdite, seulement pour pouvoir mieux contrôler les Églises (et infiltrer leurs structures), il ne s'est pas attaqué à la conception d'identité nationale tchèque qu'il soutenait, au contraire, dans la mesure où elle servait sa propre idéologie. En même temps, la rhétorique marxiste et même les restrictions et les persécutions dirigées contre les Églises bénéficiaient, au moins au début, d'un large soutien public. Vers la fin des années quarante et au cours des années cinquante et soixante, il existait en Tchécoslovaquie de vrais « croyants marxistes » qui considéraient la lutte contre l' " obscurantisme religieux " comme tout à fait positive, se réclamaient des idéaux "progressistes » en ayant recours à toute une 
panoplie de symboles parareligieux. Leur foi ne périt qu'avec l'échec du Printemps de Prague écrasé par l'invasion et l'occupation de la Tchécoslovaquie par les armées du Pacte de Varsovie, en 1968. Jusque-là, même l'idée du « socialisme à visage humain " pouvait servir d'exemple du rôle progressiste spécifique dont le hussitisme avait déjà témoigné dans un passé lointain ${ }^{15}$.

La conscience d'une identité collective, cette fois-ci nationale et socialiste, commença à se dissiper au moment où la société cessa de croire au socialisme réel, devenu simple instrument des actes politiques utilitaristes servant à soumettre le peuple au pouvoir soviétique. Durant la période dite de "normalisation ", les intérêts proprement individualistes ont pris le dessus, entraînant du même coup une corrosion rapide de la religiosité implicite. Dans la seconde moitié des années quatre-vingts et au début des années quatre-vingt-dix, une renaissance de la " religiosité paléo-durkheimienne » semblait possible, l'intérêt pour les Églises traditionnelles augmentait, mais, par la suite, il est apparu qu'il n'était que superficiel et passager (Nešpor, 2004). La majorité de la population a transféré sa foi vers des équivalents fonctionnels des organisations religieuses, mais n'a pas abandonné son aversion à l'égard des Églises rejetées au nom d'une idéologie " progressiste » qui ne se distingue de l'idéologie marxiste que par l'absence des références directes à des idées communistes. Ainsi les Tchèques ne se caractérisent pas par un athéisme, mais plutôt par une aversion de longue date envers les Églises et pour tout ce qui peut y être lié, y compris le terme « religion ». Pourquoi cette « désecclésialisation"?

Les théories de la sécularisation offrent une première explication : selon elles, l'indifférence envers la religiosité, voire sa disparition, sont la conséquence des processus de modernisation, notamment de l'industrialisation, de l'urbanisation, d'une meilleure éducation et d'une différenciation sociale. Hormis les arguments généraux qui invalident cette thèse (Gorski, 2003 : 111-113), dans le cas tchèque, il est évident que ces processus de modernisation n'ont eu lieu qu'après une désecclésialisation - entendons par là l'abandon des positions adoptées par les Églises, même si, pour la forme, les gens continuent à y adhérer ${ }^{16}$ - consécutive à un affaiblissement considérable de l'autorité ecclésiale. Le manque d'intérêt pour toute religion "officielle "s'est manifesté avant la fin du XIX e siècle et a été, en réalité, imposé aux couches populaires par le biais des lectures populaires éducatives et des autres médias de l'époque, de concert avec l'idéologie nationale du Réveil tchèque, le cas échéant comme un moyen de résistance aux groupes (religieux) qui s’y opposaient (Nešpor, 2006 : 514-520, 582ff.)

15. La concept progressiste du hussitisme en tant qu'un «socialisme avant la lettre » dans l'idéologie des communistes tchèques a déjà été canonisé par Zdenek Nejedlý (1950) dont l'œuvre a été rééditée à maintes reprises.

16. Dans le même sens, Martin Putna (1998, p. 35) dit que « les catholiques deviennent une minorité combative mais inférieure sur le plan culturel ». 


\section{Une amnésie de remémoration}

La société tchèque ne s'est pas sécularisée outre mesure uniquement (ni " automatiquement ») à cause de la modernisation, et encore moins à cause du régime communiste, mais bien avant. Le régime communiste n'a fait qu'accentuer le rejet des Églises et rendre celui-ci manifeste. Le sentiment religieux et la spiritualité tchèques n’ont pas disparu, ils se sont déplacés des structures religieuses vers une conscience nationale, étatique ou de classe, et plus tard vers des images du monde symboliques et privées. Si la religion tchèque a été, au moins pour un temps, remplacée par des formes "néo-durkheimiennes ", il est certainement permis de donner raison aux auteurs qui mettent l'anticatholicisme tchèque du $\mathrm{XIX}^{\mathrm{e}}$ siècle et du début $\mathrm{du} \mathrm{XX}^{\mathrm{e}}$ sur le compte d'une allergie aux intérêts proautrichiens, ipso facto anti-tchèques, à ceux de la haute hiérarchie ecclésiale et à l'union obsolète du trône et de l'autel dans la monarchie autrichienne/austrohongroise (Martin, 1978 : 50, 102-103). Toutefois cette explication ne suffit pas quand on sait qu'en adoptant, en 1861, l'Édit protestant, l'Autriche est devenue, au moins de jure, un pays tri-confessionnel ${ }^{17}$, et que la République tchécoslovaque, après 1918, garantissait une large liberté religieuse. Une interprétation (exclusivement) nationaliste n'explique pas l'échec de toutes les tentatives (ou au moins de celles des lendemains de la Première Guerre mondiale) d'unir les identités nationale et religieuse. À leur place, des attitudes anti-ecclésiales ont prédominé, parfois "compensées" par des tentatives de fonder de nouveaux groupes religieux à tendance individualiste et mystique (Pavlincová-Horyna, 1999 : 202-223). La société tchèque a même connu à cette époque ce qu'on pourrait appeler une spiritualité de l'époque moderne tardive - diverses tentatives de concevoir les soins du corps, la santé, le scoutisme, les randonnées dans la nature, décrites ou perçues comme de nouvelles orientations "spirituelles " ${ }^{18}$.

Les diverses Églises, et en premier lieu l'Église catholique, ont plutôt été victimes d'un trop grand nombre de "mémoires historiques » ayant perdu leurs exclusivités respectives ainsi que leur force d'identification. La société tchèque, qui avait perdu, à la fin des premiers temps modernes, son identité baroque catholique s'est trouvée confrontée aux diverses versions de la présumée histoire nationale, sans y être préparée ni en mesure de décider laquelle était la "vraie ». La « découverte " du hussitisme associée à d'autres facteurs a affaibli, au cours du XIX siècle, l'identité catholique de la nation tchèque, sans pour autant profiter aux Églises protestantes, marginales et trop faibles, ni aboutir à la création d'une

17. L'Édit protestant émancipait les luthériens et les calvinistes du catholicisme ; à ces trois confessions s'ajoutèrent plus tard l'orthodoxie, le judaïsme, et les autres religions reconnues par l'État.

18. Dans un aperçu des orientations spirituelles en Tchécoslovaquie, Marečková (1924) cite ces mouvements à côté des nouveaux mouvements religieux, le spiritisme, le mouvement antireligieux de la Libre pensée ou de nouvelles formes de la religiosité traditionnelle telles les YMCA/YWCA. 
plate-forme antireligieuse organisée ; au lieu d'une nouvelle mémoire religieuse partagée, une amnésie religieuse individuelle s'est instaurée. Dans le cas des Églises protestantes, il a été nécessaire de compléter "la tradition » de l'Union des Frères - qui divisait plus qu'elle n'unissait - par une autre "tradition » légitimante : le néo-utraquisme, toutefois sans grand succès à long terme. Les diverses interprétations du hussitisme et de l'Union des Frères étaient trop nombreuses et trop contradictoires pour être crédibles, ce qui a provoqué une rupture dans la mémoire religieuse du pays.

L' " amnésie » religieuse de la société tchèque ne date donc pas de l'époque moderne récente et ne résulte pas d'un analphabétisme religieux ou de tentatives irréfléchies des Églises de réagir à la situation contemporaine. Elle ressort plutôt des efforts excessifs faits dans le sens d'une " remémoration » religieuse, ou antireligieuse, entrepris une bonne centaine d'années plus tôt. Les croyants "pratiquants » n'avaient pas été remplacés par des «pèlerins » ou des « convertis » dont le nombre n’a augmenté que récemment (Hervieu-Léger, 1999), mais par des « athées » apparents, pour lesquels l'athéisme est une forme de résistance contre toute autorité en matière religieuse ou spirituelle.

La polarisation entre les camps cléricaux et leurs adversaires est apparue dans la société tchèque au cours du XIX siècle comme dans d'autres pays à prédominance catholique, avec toutefois une petite particularité : le camp anticlérical était largement majoritaire. En outre, par le biais d'une narration métahistorique affirmant le caractère exceptionnel du peuple tchèque, les arguments anticléricaux ont porté pendant une grande partie du XXe siècle et se manifestent encore aujourd'hui, même s'ils ne servent plus d'éléments d'intégration des groupes. La privatisation des idées transcendantes et de leurs représentations sociales ou politiques a entraîné une trop grande différenciation tant du camp « chrétien » que du camp " antichrétien » pour que leur réunion soit possible, ou qu'ils cessent de se combattre.

Dans le cas tchèque, après la chute du régime communiste ${ }^{19}$, la recrudescence de la tension entre les deux groupes est à craindre. Tandis que, par exemple en France, ces controverses tendent à faiblir et que l'on peut y observer une "sécularisation " tant du côté ecclésial que du côté laïque (Willaime, 1996), en République tchèque le relâchement postcommuniste et le retour de la religion dans l'espace public mènent à une nouvelle radicalisation. À titre d'exemple, citons la querelle qui n'en finit pas entre l'État et l'Église catholique à propos des droits de propriété concernant la cathédrale Saint-Guy au Château de Prague, les débats politiques et médiatiques sur les restitutions des biens ecclésiaux

19. Casanova (1994, pp. 109-112) voyait ainsi le cas de la Pologne où les deux camps, catholique et anticatholique, sont puissants (même s'ils sont intrinsèquement désunis) ; en République tchèque, où «les chrétiens en général » font face aux opposants des Églises, la situation est encore plus exacerbée. 
confisqués par le régime communiste, le financement des Églises ou encore le concordat avec le Saint-Siège - autant de questions qui se posent depuis bien avant le début des années quatre-vingt-dix mais auxquelles aucune réponse n'a encore été apportée. La situation est d'autant plus grave que des éléments importants constituant les deux camps manquent d'unité et refusent de se soumettre à toute autorité supérieure. Leurs "péchés du passé " leur étant reprochés, les Églises et leurs organisations locales, sociales ou autres ne peuvent donc pas jouer le rôle de vicarious memory. La dévotion ecclésiale, voire le christianisme en général sont identifiés à la répression du " hussitisme progressiste ", sans qu'on cherche à connaître la vraie nature, l'évolution et l'état actuel de la religiosité catholique, laquelle s'en trouve rejetée a priori. D'un autre côté, les « religions de remplacement ", dont il ne reste plus que des idéologies sans effet d'intégration sociale, ne fonctionnent pas mieux. Tandis que la « religion »- ou tout ce qu'on peut ainsi désigner - est devenue, pour les deux camps, un simple symbole du combat pro- ou anticlérical, la « spiritualité » privatisée et l'intérêt pour les formes «non religieuses" de la transcendance ne cessent de gagner du terrain.

Zdeněk R. NEŠPOR

Prague, Institut sociologique de l'Académie des sciences zdenek.nespor@soc.cas.cz

\section{Bibliographie}

Berger Peter L., 1992, A Far Glory. The Quest for Faith in an Age of Credulity, New York, Free Press.

Borowik Irena, 2002, "The Roman Catholic Church in the Process of Democratic Transition: The Case of Poland ", Social Compass, 49-2, pp. 239-252.

Borowik Irena, Tomka Miklós, (eds.), 2001, Religion and Social Change in Post-Communist Europe, Kraków, Nomos.

Bruce Steve, 2002, God is Dead. Secularization in the West, Oxford, Blackwell.

Casanova José, 1994, Public Religions in the Modern World, Chicago, London, University of Chicago Press.

CuHra Jaroslav, "KSČ, stát a římskokatolická církev (1948-1989) ", Soudobé dějiny, 8-2/3, pp. 267-293.

CZAKó Ambrose, 1925, The Future of Protestantism with Special Reference to SouthEastern Europe, London, G. Allen \& Unwin.

DAviE Grace, 2000, Religion in Modern Europe. A Memory Mutates, Oxford, Oxford University Press.

,- 2003, "The evolution of the sociologie of religion. Theme and variations ", in Dillon M., (ed.), Handbook of the Sociology of Religion, Cambridge, Cambridge University Press, pp. 61-75.

Dillon Michele, (ed.), 2003, Handbook of the Sociology of Religion, Cambridge, Cambridge University Press.

Ducreux Marie-Élisabeth, 1999, "Exil et conversion. Les trajectoires de vie d'émigrants tchèques à Berlin au 18 e siècle ", Annales. Histoire, Sciences Sociales, 54-4, pp. 915-944. 
GaUtier Mary L., 1997, "Church Attendance and Religious Belief in Postcommunist Societies ", Journal for the Scientific Study of Religion, 36-2, pp. 289-296.

GORSKI Philip S., 2003, "Historicizing the secularization debate: an agenda for research ", in Dillon M., (ed.), Handbook of the Sociology of Religion, Cambridge, Cambridge University Press, pp. 110-122.

GrajewsKi Andrzej, 1999, Kompleks Judasza. Kosciol zraniony, Poznań, W drodze.

Hamplová Dana, 2000, Náboženství a nadpřirozeno ve společnosti. Mezinárodní srovnání na základě empirického výzkumu ISSP, Praha, Sociologický ústav AV ČR.

Hervieu-LÉGER Danièle, 2003, La religion pour mémoire, Paris, Éditions du Cerf.

-, 1999, Le Pèlerin et le converti. La religion en mouvement, Paris, Flammarion.

Holy Ladislav, 1996, The Little Czech and the Great Czech Nation. National Identity and Post-Communist Social Transformation, Cambridge, Cambridge University Press.

HrejSA Ferdinand, 1912, Česká konfesse, její vznik, podstata, dějiny, Praha, ČAVU.

Hroch Miroslav, 2003, «Die Tschechische nationale Mobilisierung als Antwort auf die Identitätskrise um 1800 ", in Dann O., Hroch M., Koll J., (eds.), Patriotismus und Nationsbildung am Ende des Heiligen Römischen Reiches, Köln, SH-Verlag, pp. 191-205.

Institoris Mossóczi Michal, 1783, Listownj Odpowěd k Augspurského Wyznánj Cžechìm a Morawanim..., Praha, J. T. Höchenberger.

KADlECová Erika, 1967, Sociologický výzkum religiozity Severomoravskébo kraje, Praha, Academia.

-, 1972, "Czechoslovakia ", in Mol H., (ed.), Western Religion. A Country by Country Sociological Inquiry, The Hague, Paris, Mouton, pp. 117-134.

KaISEROVÁ Kristina, 2003, Konfesni myšlení českých Němcủ v 19. a počátkem 20. století, Úvaly u Prahy, Ve stráni.

Kalivoda Robert, 1961, Husitská ideologie, Praha, NČSAV.

KuTNar František, 2003, Obrozenské vlastenectví a nacionalismus. Příspěvek k národnímu a společenskému obsahu češství doby obrozenské, Praha, Karolinum.

LENFANT Jacob, [1731] 1783-84, Geschichte des Hussitenkriegs und des Konziliums zu Basel, Preßburg, J. M. Landerer.

LUKÁšEK Josef, 1927, Bedřich Vilém Košut a náboženské poměry v revoluční době r. 1848 a za vlády absolutismu, Praha, V. Horák.

LuŽNÝ Dušan, NAVRÁTIlová Jolana, 2001, "Religion and Secularization in the Czech Republic ", Czech Sociological Review, 9-1, pp. 85-98.

MACEK Josef, 1952, Tábor v husitském revolučním hnutí I-II, Praha, Rovnost.

MAREČKova Josefina, 1924, Duchovné prúdy v našej republike, Bratislava, Bratislavská pošta.

Martin David, 1978, A General Theory of Secularization, Oxford, Blackwell.

-, 1991, "The Secularization Issue: Prospect and Retrospect ", British Journal of Socio$\log$, , 42-4, pp. 465-474.

Martin David, 2005, On Secularization. Towards a Revised Theory, Aldershot, Ashgate.

MASARYK Tomáš Garrigue, [1895] 1990, Česká otázka. Snaby a tužby národního obrození, Praha, Svoboda.

MAUR Eduard, 2003, 12.5.1743. Marie Terezie. Korunovace na usmírenou, Praha, Havran.

Mol Hans, (ed.), 1972, Western Religion. A Country by Country Sociological Inquiry, The Hague, Paris, Mouton. 
Nejedlý Zdeněk, [1946] 1950, Komunisté dědici velikých tradic českého národa, Praha, Československý spisovatel.

NešPor Zdeněk R., 2004, "Religious Processes in Contemporary Czech Society ", Sociologický časopis/Czech Sociological Review, 40-3, pp. 277-295.

-, 2006, Náboženství na prahu nové doby. Česká lidová zbožnost 18. a 19. století, Ústí nad Labem, Albis international.

-, 2007, "Brněnský výzkum současné religiozity z roku 1930: současná interpretace ", Religio, 15-1, pp. 87-108.

Norris Pippa, Inglehart Ronald, 2004, Sacred and Secular. Religion and Politics Worldwide, Cambridge, Cambridge University Press.

PABIAN Pavel, 2005, « Katolické ghetto nebo katolický národ? České katolické vlastenectví na konci 19. století », Kudèj, 7-1/2, pp. 93-99.

Pavlincová Helena, Horyna Břetislav, 1999, Filosofie náboženství. Pokus o typologii, Brno, Masarykova univerzita.

PeroutKa Ferdinand, [1936] 1991, Budování státu, Praha, Lidové noviny.

Pollack Detlef, 2003, "Religiousness Inside and Outside the Church in Selected PostCommunist Countries of Central and Eastern Europe ", Social Compass, 50-3, pp. 321-334.

PuTNA Martin C., 1998, Česká katolická literatura v evropském kontextu. 1848-1918, Praha, Torst.

RÁdl Emanuel, 1922, La question religieuse en Tchéchoslovaquie, Prague, Gazette de Prague.

Ramet Sabrina P., 1998, Nihil Obstat. Religion, Politics, and Social Change in EastCentral Europe and Russia, Durham, London, Duke University Press.

RÉMOND René, 1998, Religion et société en Europe. Essai sur la sécularisation des sociétés européennes aux XIX ${ }^{e}$ et XX ${ }^{e}$ siècles (1798-1998), Paris, Éditions du Seuil.

Rочко Kaspar, 1781-85, Geschichte der großen allgemeinen Kirchenversammlung zu Kostniz, Gräz, Prag.

ŘíčAn Rudolf, 1948, Od úsvitu reformace $k$ dnešku, Praha, YMCA.

SeKera Václav, 1932, "Náboženské přesuny na Ostravsku ", Sociální problémy, 2-1, pp. 1-25.

STRŽíneK Antonín, (ed.), 1921, Na nové cesty. Kam od Řima?, Praha, Osvěta.

ŠMAHEL František, 1971, Idea národa v husitských Čechách, Česká Budějovice, Růže.

TAYLOR Charles, 2002, Varieties of Religion Today. William James Revisited, Cambridge, London, Harvard University Press.

Vunas Vít, 1993, Jan Nepomucký. Česká legenda, Praha, Mladá fronta.

Weigel George, 2004, "Europe's Problem - And Ours », First Things, 140, pp. 18-25.

Willaime Jean-Paul, 1996, « Laïcité et religion en France », in DAVIE G., Hervieu-LÉGer D., (éds.), Identités religieuses en Europe, Paris, La Découverte, pp. 153-171.

WINTER Eduard, 1943, Der Josefinismus und seine Geschichte. Beiträge zur Geistesgeschichte Österreichs 1740-1848, Brünn, R. M. Rohrer.

WysокомÝtskÝ Antonjn, 1849, Početj roku 1620 a sledj geho, čili řáděnj Gezuitù w Čechách a na Morawě, Praha, Česko-bratrský hlasatel.

Zuber Rudolf, 2003, Osudy moravské církve v 18. století II., Olomouc, Matice cyrilometodějská. 


\section{Résumé}

L'article traite de la position de la religion dans la société tchèque actuelle, montrant un taux élevé d'athéisme déclaré, dont la vrai cause se trouve, selon l'auteur, dans une aversion envers les Églises et dans la propagation de formes religieuses/spirituelles privatisées. Dans le cas tchèque, l' "amnésie " religieuse n'est pas une conséquence de la diminution de l'intérêt pour la religion ni d'un "analphabétisme religieux" de l'époque moderne tardive. Elle est une manifestation de la résistance contre des tentatives, trop nombreuses et souvent contradictoires imposées par le pouvoir, de revitaliser une "mémoire " religieuse, qu'on observait en masse au XIXe siècle déjà et qui s'est perpétuée, sous une forme différente, pendant une grande partie du XXe siècle. La résistance à ces pressions, leurs différenciation et déconstruction actuelles n'aboutissent toutefois pas à une plus grande tolérance entre croyants et non-croyants, mais au contraire exacerbent la lutte entre divers partisans des deux camps.

Mots-clés: République tchèque, taux de religiosité, mémoire religieuse, résistance religieuse.

\section{Abstract}

The paper provides information on the state of religion in contemporary Czech Republic, including the extraordinary high rates of declared atheism, which essence the author describes in terms of anticlericalism and widespread privatized religious/ spiritual forms. In the Czech case, there is emphasized that religious "amnesia" did not emerged as a result of reduction of interest in religion and "religious illiteracy" in the late modernity, but as an expression of hostility towards too many mutually inconvertible efforts of revitalization of religious "memories" forcibly coming from above in the $19^{\text {th }}$ century, and mutatis mutandis also in the major part of the $20^{\text {th }} \mathrm{cen}$ tury. Popular dislike for such pressures, their recent differentiation and deconstruction have not lead to wider tolerance between religious and unreligious parts of the society, however, they have sharpened mutual struggle among (various) devotees of both sides.

Key words: Czech Republic, religious rate, religious memory, religious resistance.

\section{Resumen}

El artículo aborda la posición de la religión en la sociedad actual de la República Checa, mostrando una tasa elevada de ateismo declarado, cuya verdadera causa se encuentra, según el autor, en una aversión hacia las Iglesias y en la propagación de las formas religiosas/espirituales privatizadas. En el caso checo, la "amnesia" religiosa no es una consecuencia de la disminución del interés por la religión ni del "analfabetismo religioso" de la época moderna tardía, sino una manifestación de la resistencia contra los intentos, demasiado numerosos y frecuentemente contradictorios, impuestos desde el poder, de revitalizar una "memoria" religiosa que se observaba en masa en el siglo XIX y que se perpetúa, bajo una forma diferente, durante gran parte del siglo XX. La resistencia a estas presiones, su diferenciación y deconstrucción actuales no desembocan en una mayor tolerancia entre creyentes y no creyentes, sino que por el contrario exacerban la lucha entre diversos partidarios de los dos campos.

Palabras clave: República Checa, tasa de religiosidad, memoria religiosa, resistencia religiosa. 